\title{
Klinik biyokimyada biyolojik varyasyon: referans değişim değeri ve bireysellik indeksi
}

\section{Biological variation in clinical biochemistry: reference change value and Individual ındex}

\author{
Erdem ÇOKLUK* $\square$
}

Sakarya Üniversitesi, Tıp Fakültesi, Tıbbi Biyokimya Anabilim Dalı, Sakarya/TÜRKiYE

\begin{abstract}
Öz
Değişiklik (varyasyon), yaşam süresinin ve ritmik biyolojik döngülerin bir sonucu olabilmesine rağmen, birçok analitin biyolojik çeşitliliği, en basit modelde, homeostatik bir ayar noktasının etrafındaki rastgele dalgalanma olarak tanımlanabilir. Biyolojik varyasyon birey içi ve bireyler arası bileşenlerinin büyüklüğünü tanımlamak için çok sayıda koşulu basit deneysel yöntem ile açıklamaktadır. Bu deneysel teknik kullanılarak üretilen ortalama birey içi ve bireyler arası biyolojik değerler ile ilişkili olarak RCV(referans değişim değer) ve II(bireysellik indeksi) hakkında bilgi ve yorum yapılabilmektedir. Ayrıca, geleneksel popülasyona dayalı referans değerlerin kullanımı ve uygunluğu, test sonuçlarını bildirmenin en iyi yolunu, numune toplamanın en uygun şeklini ve en büyük potansiyel kullanımı olan test prosedürünü belirlemeyi, epidemiyolojide kullanılan güvenilirlik katsayısının hesaplanmasını, herhangi bir yeni test prosedürünün geliştirilmesini, belirtilen bir olasııık ile belirli bir yüzde içindeki homeostatik ayar noktasını tahmin etmek için gereken örnek sayısının belirlenmesi için kullanılabilmektedir. Bu ve buna benzer kullanım kolaylıklarının sağlanmasında yer almasından dolayı, bu derlemede biyolojik varyasyon, referans değişim değeri ve bireysellik indeksi hakkında bilgi sunmayı amaçladık.
\end{abstract}

Anahtar kelimeler: Biyolojik varyasyon; referans değişim değeri; bireysellik indeksi

\section{Abstract}

Although variation may be the result of life cycle and rhythmic biological cycles, the biodiversity of many analytes can be described as the simplest model, a random fluctuation around a homeostatic setpoint. Biological variation describes a number of conditions with simple experimental methods to define the magnitude of the intra- and inter-individual components. Information and comments can be made about RCV (reference change value) and II (individuality index) in relation to the mean intra- and inter-individual biological values generated using this experimental technique. Furthermore, the use and suitability of conventional, population-based reference values, the best way to report test results, determining the test method that is the most appropriate form and the greatest potential use of the sample collection, calculating the reliability coefficient used in the epidemiology, the development of any new test procedure, it can be used to determine the number of samples required to estimate the homeostatic setpoint in a given percentage. In this review, we aimed to present information about biological variation, reference change value and individuality index.

Keywords: Biological variation; reference change value; individuality index

Sorumlu Yazar*: Erdem Çokluk, Sakarya Üniversitesi, Tıp Fakültesi, Tıbbi Biyokimya Anabilim Dalı, Sakarya/TÜRKIYE E-mail: erdemcokluk@sakarya.edu.tr

ORCID: 0000-0002-6205-5109

Gönderim: 06.10.2018 Kabul : 29.07.2019

Doi: $10.18663 /$ tjcl.467978 


\section{Giriş \\ Biyolojik varyasyon}

Değişiklik (varyasyon), yaşam süresinin ve ritmik biyolojik döngülerin bir sonucu olabilmesine rağmen, birçok analitin biyolojik çeşitliliği, en basit modelde, homeostatik bir ayar noktasının etrafındaki rastgele dalgalanmalar olarak tanımlanabilir (1). Biyolojik varyasyon verileri biyolojik belirteçlerin potansiyel klinik önemini değerlendirmek için gerekli bir unsur olarak düşünülmektedir.

\section{Biyolojik varyasyonun doğası ve bileşenleri}

Bazı analitler, kişinin ömrü boyunca değişmekte, bu da referans aralıkların belirlenmesinde kronolojik yaşa göre tabakalaştırma yapılmasına neden olmaktadır. Buna ek olarak, bazı analitlerin öngörülebilir biyolojik döngüleri veya ritimleri bulunmaktadır. Bu döngüleri en az;

- Günlük ritimlerin bulunduğu, günün farklı zamanları

- Aylık döngülerin bulunduğu, ay boyunca farklı zamanlar

- Farklı mevsimler (etkileyen faktör olduğunda) olarak belirtilebiliriz.

Bu doğal döngüsel değişimler, aynı bireyden elde edilen, seri olarak ölçümleri yapılan analitler sonuçlarının sayısal değerlerindeki (seri olarak ölçülen) farklara katkıda bulunacaktır (1). Klinik olarak önemli döngüsel ritimleri bulunmayan birçok analit için, bu önemli bir sorun değilken, bu ritimleri bilmek hayati önem taşımaktadır (1). Hasta numuneleri, test sonucunun uygulanacağı klinik amaç için uygun döngüde toplanmalıdır. Beklenen/bilinen bir ritim veya döngünün bulunmaması, hastalığın varlığı ile ilgili önemli ipuçları verebilmekte ve bu da dinamik fonksiyon testlerinin temelini oluşturmaktadır (1).

Herhangi bir kişinin test sonuçları üç faktöre bağlı olarak zamanla değişmektedir:

- Pre-analitik etkiler; örneğin postür ve turrnike uygulama süresi gibi örnekleme için kişinin hazırlanması veya örnek toplama işlemi süreci değiştirebilmekte,

- Analitik rasgele hata (hassasiyet) - ve muhtemelen sistematik hata (örneğin kalibrasyondan kaynaklanan bias değişiklikleri),

- Homeostatik ayar noktası çevresindeki doğal rastgele biyolojik çeşitlilik (bu birey içi veya bireysel biyolojik varyasyon olarak adlandırılmaktadır) (1).

Aynı testi için farklı bireylerden ölçülen her bir sonuç birbirinden faklı olacaktır. Çünkü, bireylerin homeostatik ayar noktaları genellikle birbirinden farklı olmakta, bu fark da bireyler arası biyolojik varyasyon olarak tanımlanmaktadır (1).

\section{Biyolojik varyasyon ile ilgili terimler}

Varyasyon, yaşam süresinin ve ritmik biyolojik döngülerin bir sonucu olabilmesine rağmen, birçok analitin biyolojik çeşitliliği, en basit modelde, homeostatik bir ayar noktasının etrafındaki rastgele dalgalanma olarak tanımlanmaktadır (2).

Homeostatik ayar noktası: Bir bireyin sonuçlarının zaman içerisinde etrafında dolaştığı değer olarak tanımlanmaktadır (2).

Homeostatik model: Analitin rastgele davrandığını ve her bireyin homeostatik bir ayar noktasına sahip olduğunu varsayan zaman serileri analizi için bir model olarak tanımlanmaktadır (2).

Birey içi biyolojik varyasyon (CVI): Birey içi veya bireysel biyolojik çeşitlilik, bireylerin homeostatik ayar noktası etrafındaki ortalama rastgele dalgalanmadır (2).

Bireyler arası biyolojik varyasyon (CVG): Bireyler arası biyolojik çeşitlilik, bireylerin belirlenen homeostatik ayar noktaları arasındaki fark olarak tanımlanmaktadır (2). Matematiksel terimlerle birlikte birey içi biyolojik varyasyon ve bireyler arası biyolojik varyasyon genellikle sırasıyla; CVI ve CVG şeklinde varyasyonun katsayısı (CV) olarak ifade edilmektedir (2).

Referans değişim değeri (RCV): Bir kişinin seri sonuçlarında önemli bir değişiklik olmadan önce, önceden belirlenmiş bir olasılıkta aşılması gereken değer (2). Bir başka deyişle, iki sonuç arasındaki değişikliğin klinik önemini betimleyen sayısal değere klasik olarak kritik fark veya referans değişim değeri denmektedir (3).

Bireysellik indeksi (II): Varyasyonun biyolojik bileşenlerinin basit oranı olarak hesaplanan birey içi varyasyonun bireyler arasına oranı olarak tanımlanmaktadır $(2,3)$.

Sabit limit: Klinik hareketin bir ölçütü, yeterlilik testleri ya da dış kalite değerlendirme yöntemlerinin kabul edilebilirliği için bir kriter olarak kullanılan, bazı farklı yöntemlerle belirlenen bir değer olarak tanımlanmaktadır (2).

Pre-analitik varyasyon: Bir test sonucunu elde etme sürecinin analiz öncesi kısmından kaynaklanan varyasyon olarak tanımlanmaktadır (2).

Analitik varyasyon (CVA): Bir bireyde ölçümü yapılan tüm analitlerden elde edilen değerlerin farklı zamanlardaki farklı sonuçların toplam varyasyonuna katkıda bulunan, kararsızlık ve ön yargı (bias) bileşenlerinden oluşan, analiz işleminin doğasında yer alan varyasyondur. Toplam analitik hata, ölçüm belirsizliği (I: Impresizyon) ve doğruluktan sapma (B: Bias) olarak ifade edilen analitik özelliklere ait tahminlerin birlikte etkilediği toplam hata ile belirlenmektedir. Bu analitik özellikler CVA'nın ana kaynakları olarak kabul edilmektedir (4)(17). Laboratuvar pratiğinde ölçüm belirsizliği, tekrarlı analizler ve dağılımın standart sapması (SD) veya varyasyon katsayısının (CV) hesaplanmasıly belirlenmektedir.

Toplam izin verilebilir hata (TEa): Toplam hata için kalite belirteci olarak ifade edilmekte, genellikle; bias +1.65 * kesinlik, olarak tanımlamakta, ancak farklı şekillerde de ifade edilebilmektedir. 
Genel formül TE = bias $+n$ * kesinliktir. (n: istenen güven aralığı için sabit değerdir).

Toplam analitik hata $=$ Rasgele Hata + Sistematik Hata

İdeal koşullar altında toplam analitik hata sıfıra eşittir, ancak I, büyük ölçüde yöntem bağımlıdır ve kullanılacak yöntemin dikkatli seçimiyle azaltılabilirse de hiçbir zaman sıfır olamamaktadır. Yalnızca sistematik hata değişimi ( $\Delta S E)$ sıfır olabilir $(\Delta S E \geq 0)$, çünkü random hata değişimi ( $\triangle R E)$ her zaman sıfırdan büyüktür $(\triangle R E>0)$, bu durum hatanın doğasından kaynaklanmaktadır. Total hatanın sıfırdan büyük olması kaçııılmaz olduğu için her bir saptamanın TE'si belirlenen bir sınırın altında olmalıdır. Bu sınır, "izin verilen toplam analitik hata" (TEa) olarak adlandırılmakta ve bir klinik laboratuvarda belirlenen her analit için farklı olmaktadır (1).

\section{Normal değer ve test sonuçlarının yorumlanması}

Klinik laboratuvarlarda elde edilen test sonuçlarının yorumlanması sıklıkla topluma dayalı referans aralıklarla karşılaştırılarak yapılmaktadır (1).

Belirli bir test için verilen referans aralığı içindeki tüm sonuçların 'normali' yansıttığı düşüncesi her durum için doğru olmayabilir. Buna göre "normal değer" terminolojisinin kullanımı günümüzde terk edilmiştir. Sağlıklı ve hastalıklı teriminin laboratuvar tarafından değerlendirilebilmesi için Uluslarası Klinik Kimya Federasyonu (IFCC), normal değer yerine referans değer ve bununla ilişkili olarak referans birey, referans sınır, referans aralık ve gözlenen değerler terimlerinin kullanılmasını önermektedir (5).

\section{Biyolojik varyasyon verileri ile ilgili semboller ve formüller}

Biyolojik varyasyon ve ilişkili parametreler için yaygın olarak kullanılan terim ve semboller Fraser (6)'ın çalışmasında belirtilmiş olup, yayınlarda yer alan orijinal isimlendirme korunmuş olan tablo 1'de yer almaktadır. Fakat bu sembollerin kullanımı ile ilgili henüz bir harmonizasyon sağlanamamıştır (7). Bu farklılık ile ilgili olarak Ana-Maria Simundic (8)ve ark. 2009-2013 yılları arasında Web of Science veritabanında yer alan, alanında popüler 13 dergide "biyolojik varyasyon" anahtar sözcüğü ile yaptıkları aramada toplam 241 makaleye ulaşmış, bunların 125'inin biyolojik varyasyon ile ilişkilendirilmiş, belirlenen 125 makaleden 62'sinin de biyolojik varyasyon terim ve semboller ile direkt ilişkili olduğu saptanmıştır. Elde edilen bu verilerden bireysel kullanım için 68 terim ve 25 sembol, gruplar için ise 47 terim ve 18 sembol'un uygun olarak kullanıldığını tespit etmişlerdir (Tablo 2)(8). AnaMaria Simundic (8) ve ark. tutarlı kullanım amacıyla biyolojik varyasyon bileşenleri ve ilişkili diğer parametreleri için aşağıda yer alan terim ve sembollerin kullanımı önermişlerdir.

\begin{tabular}{|c|c|c|c|}
\hline Terim & Terim sıklığı & Sembol & Sembol sıklığı \\
\hline \multicolumn{4}{|l|}{ Bireyler için uygulanabilir } \\
\hline Within-subject biological variation & 18 & CVI & 35 \\
\hline Intraindividual biological variation & 11 & $\mathrm{CVw}$ & 8 \\
\hline Intraindividual variation & 11 & $\mathrm{CVi}$ & 7 \\
\hline Intraindividual variation & 10 & $C V w$ & 6 \\
\hline Within-subject variation & 9 & CVW & 6 \\
\hline Within-subject coefficient of variation & 5 & $\mathrm{CVi}$ & 6 \\
\hline Intraindividual variability & 4 & CVwithin-subject & 3 \\
\hline Within-person biological variation & 4 & CVbiological & 3 \\
\hline Within-person variation & 4 & $\mathrm{CVb}$ & 3 \\
\hline Intraindividual biological variation & 3 & & \\
\hline Intraindividual CV & 3 & & \\
\hline Within-subject CV & 3 & & \\
\hline Within-subject biological variation & 3 & & \\
\hline \multicolumn{4}{|l|}{ Applicable to groups } \\
\hline Between-subject biological variation & 16 & $\mathrm{CVg}$ & 29 \\
\hline Interindividual variation & 14 & $\mathrm{CVg}$ & 7 \\
\hline Between-subject variation & 7 & $\mathrm{CVg}$ & 5 \\
\hline Interindividual biological variation & 5 & $\mathrm{CVb}$ & 4 \\
\hline Interindividual CV & 5 & $\mathrm{CVb}$ & 2 \\
\hline Interindividual variability & 5 & & \\
\hline Between-person variation & 4 & & \\
\hline Between-subject coefficient of variation & 4 & & \\
\hline Interindividual variation & 4 & & \\
\hline
\end{tabular}




\begin{tabular}{|c|c|c|c|}
\hline Kısaltma & Tanımlama & Formül & \\
\hline S2T & Tüm ölçümlerin total varyansı & $(S 2 A+S 2 I+S 2 G)$ & \\
\hline $\mathrm{S} 2 \mathrm{I}+\mathrm{A}$ & Ortalama birey içi total varyans & & \\
\hline$S 2 A$ & Ortalama çalışma içi analitik varyans & & \\
\hline S2I & Ortalama birey içi BV & $(S 2 I+A-1 / 2 S 2 A)$ & \\
\hline $\mathrm{S} 2 \mathrm{G}$ & Bireyler arası BV & $\begin{array}{l}([(2 \mathrm{kr}-1) / 2 \mathrm{k}(\mathrm{r}-1)][S 2 \mathrm{~S}-\mathrm{S} 2 \mathrm{~A}-[(2 \mathrm{kr}-2) /(2 \mathrm{kr} \\
-1)] \mathrm{S} 2 \mathrm{I}\}, \mathrm{k} \text { birey başına toplanan numune } \\
\text { sayısı r birey sayısı) }\end{array}$ & \\
\hline CVT & Birey içi total varyasyon katsayısı & & \\
\hline CVA & Analitik varyasyon katsayısı & & \\
\hline CVI & Birey içi biyolojik varyasyon katsayısı & & \\
\hline CVG & Bireyler arası biyolojik varyasyon katsayısı & & \\
\hline II & Bireysellik indeksi & $(\mathrm{S} 2 \mathrm{I}+\mathrm{A} / \mathrm{S} 2 \mathrm{G})$ & \\
\hline $\mathrm{RCV}$ & Referans değişim değeri & & $(2.77(\mathrm{CVA} 2+\mathrm{CV} / 2) 0.5)$ \\
\hline D & İstenen yakınlık derecesi & & \\
\hline$n$ & $\begin{array}{l}\text { İstenen yakınlık derecesinde homeostarik } \\
\text { ayar noktasını tahmin etmek için gerekli } \\
\text { numune sayısı (D) }\end{array}$ & $1.962(\mathrm{CVA} 2+\mathrm{CVI} 2) / \mathrm{D} 2]$ & \\
\hline $\mathrm{IH}$ & $\begin{array}{l}\text { Heterojenite indeksi (gözlenen CVT 'nin } \\
\text { teorik CV) }\end{array}$ & $\begin{array}{l}(\mathrm{CVT} /[(2 / \mathrm{k}-1) 1 / 2 \times 100], \mathrm{k} \text { birey başına alını } \\
\text { numune sayısı) }\end{array}$ & \\
\hline
\end{tabular}

- Birey içi biyolojik varyasyon (CVI): Bir gruptaki bireylerden toplanan varyasyon olarak tahmin edilen tek bir birey içindeki varyasyon.

- Bireyler arası biyolojik varyasyon (CVG): Bir grup bireyin merkezi eğilimleri arasındaki varyasyon.

- Analitik varyasyon (analitik kararsızlık) (CVA): türetme ve türeme modu (tekrarlanabilirlik, güvenilirlik veya toplam gibi) ve analiz sayısı, çalışma sayısı ve zaman periyodu verilerek daima açıklığa kavuşturulmalıdır.

- Referans değişiklik değeri (RCV): Bir bireyden elde edilen 2 seri sonuçtan önemlilik için gerekli olan fark, her zaman kullanılan formüle, yani 21/2Z X (CVA2-CVI2) $1 / 2$ eşlik etmeli; olasılığı ve farkların tek yönlü veya çift yönlü olarak hesaplandığını belirtmek için Z-skoru tanımlanmalıdır.

- Bireysellik indeksi (II): Analitik ve birey içi varyasyonun bireyler arası biyolojik varyasyona oranı olarak tanımlanmakta ve her zaman hesaplama için kullanılan formüle eşlik etmelidir: tercih edilen (CVA2 CVI2)1/2 / CVG veya şimdi daha kullanışlı görünen CVI / CVG 'dir (8).

\section{Biyolojik varyasyon bileşenlerinin belirlenmesi ve çalışma prosedürleri}

Biyolojik varyasyonun birey içi ve bireyler arası bileşenlerinin büyüklüğünü tanımlamak için çok sayıda koşul olmasıyla birlikte aşağıda yer alan basit deneysel yöntem sıklıkla tercih edilmektedir (1).

1. Görünürde sağlıklı gönüllülerden oluşan küçük bir grubu alınır (ya da araştırılan analiti etkileyen herhangi bir hastalığa sahip bireylerden).

2. Her bireyden düzenli aralıklarla bir dizi numune alınır, preanalitik varyasyon en aza indirilir.

3. Numuneler analiz için saklanır.

4. Analitik varyasyon kaynakları en aza indirgenerek tekrarlı analiz yapılır.

5. Verilerin büyük bölümünden farklı olan sonuçlar dışlanır.

6. Analitik, birey içi ve bireyler arası biyolojik varyasyon bileşenleri varyansın basit istatistik analiz tekniği ile (ANOVA) belirlenir (1).

\section{Biyolojik varyasyon verilerinin kullanım alanları}

$\mathrm{Bu}$ deneysel teknik kullanılarak üretilen ortalama birey içi ve bireyler arası biyolojik değerler ile ilişkili RCV ve II hakkında bilgi ve yorum yapılabilmektedir (1). Biyolojik varyasyonun bileşenleriyle ilgili veriler, aşağıdaki özelliklerin belirlenmesinde kullanılmaktadır (1). Biyolojik varyasyon verilerinin laboratuvar süreçlerinde çeşitli kullanım alanlarının şematik hali şekil 1'de gösterilmiştir. 


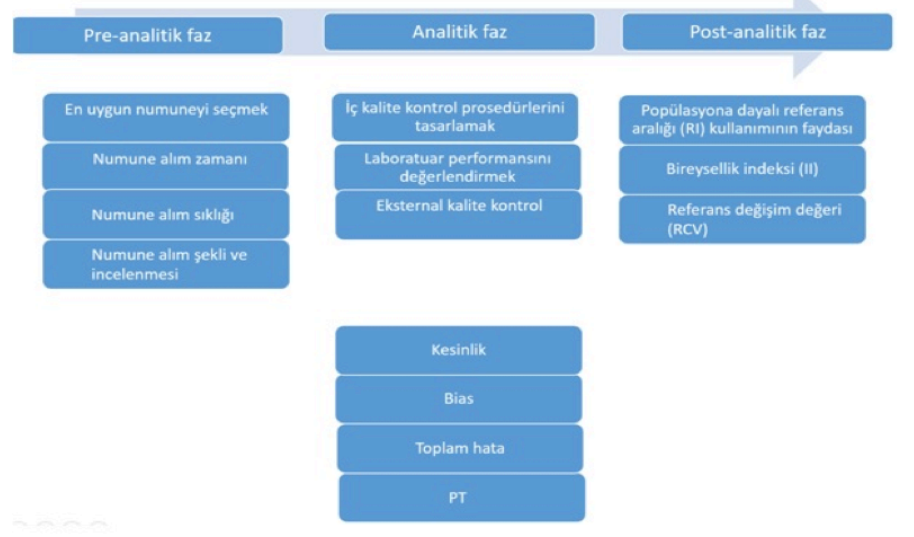

Şekil 1. Biyolojik varyasyon verilerinin laboratuvar süreçlerinde çeşitli kullanım alanları

- Kesinlik

- Bias

- İzin verilen toplam hata

- Yöntemler arasında izin verilen fark

- Bir bireyin seri sonuçlarında meydana gelen anlamlı değişiklik görülmeden önceki (referans değişiklik değeri) değişiklik tespti

- Bir kişinin seri sonuçlarındaki bir değişikliğin istatistiksel olarak anlamlı olup olmadığını belirlemek

- Kalite yönetiminde kullanılmak üzere nesnel delta-kontrol değerlerini üretmek

\section{Birey içi ve bireyler arası biyolojik varyasyonu karşılaştırmak,}

- Geleneksel popülasyona dayalı referans değerlerin kullanımının faydası ve uygunluğu değerlendirmeyi; örneğin yaş ve cinsiyete göre tabakalı referans değerlerin neden klinik karar vermeyi geliştirdiğini açıklamayı,

- Test sonuçlarını bildirmenin en iyi yolunu, en iyi numune toplamayı ve en büyük potansiyel kullanımı olan test prosedürünü belirlemeyi,

- Epidemiyolojide kullanılan güvenilirlik katsayısının hesaplanmasını,

- Herhangi bir yeni test prosedürünün geliştirilmesini,

- Belirtilen bir olasılık ile belirli bir yüzde içindeki homeostatik ayar noktasını tahmin etmek için gereken örnek sayısının belirlenmesi ve şekil 9'da yer alan diğer amaçları sağlamak için de kullanılabilmektedir (1).

\section{Sağlık ve hastalık durumlarında Biyolojik varyasyon}

Laboratuvarlarda sıkça ölçülen çoğu analitin BV'si ile ilgili birçok araştırma yapılmıştır (9-12). Bu çalışmalardan bazılarında serum ve 24 saatlik idrardaki birçok analit değerlerinin CVI'sı incelenmiştir (10). Genel olarak birey sayısı, kullanılan yöntem, popülasyon ve çalışmaya ait zaman ölçeği değişse de CVI tahminlerinin birbirine yakın olduğu gözlenmiş, CVI değerlerinin ise daha çok tekrar sayılarından etkilendiği belirtilmiştir (13). Benzer çalışmalarla hemostatik mekanizmaların yaşlanma süreci boyunca azaldığı ve BV'un yaşla birlikte arttığı gösterilse de, BV'nin genç ve yaşlı popülasyonda farklı olduğuna dair fazla sayıda kanıt bulunamadığı da bildirilmektedir (10). Ricos ve arkadaşları (12) 15 bilimsel dergide yer almış 45 yayından elde edilen ve 34 hastalığa ait yaklaşık 66 parametreyi içeren bir veri tabanı hazırlamışlardır. Vakaların çoğunda hastalık grubundaki CVI değerlerinin sağlıklı grup ile aynı düzeyde olduğu gözlenmiştir. Çalışılan analitlere ait hasta bireylerden elde edilen CVı dağılımlarının, sağlıklı bireylerde gözlenen CVI dağılımının içinde yer aldığı belirtilmiştir. Parametrelerin kullanılabilir ölçümlerinin az sayıda olması ve çalışma yöntemlerinin farklılıklar göstermesi nedeniyle bu veriler sabit istatistiksel karşılaştırma için kullanılmamaktadır. Gözlenen farklılıkların klinik uygulamalar üzerindeki etkisinin az olduğu ve çoğu durumda hastalığa özgü anlamlı farklılıkları belirlemenin gerekmediği de vurgulanmaktadır $(13,14)$. Bununla birlikte, literatür taramaları sonucunda BV'lerin bir kısmının bazı hastalık tanıları almış kişilerde hesaplandığında, sağlıklı bireylerde olduğu gibi sabit bir değer olduğu da belirtilmektedir. Sole'tormos G. ve ark. yaptığı çalışmada (14) sağlıklı ve prostat kanseri olan bireylerde BV'nin aynı olduğunu bildirmişlerdir. Ricos ve ark. (12) karaciğer hastalıklarında alfa-fetoprotein, paget hastalığında alkalin fosfataz, over kanseri CA125 ve CA15.3, kolorektal kanserde karsinoembriyonik antijen, böbrek hastalığında kreatinin, diabetes mellitusta HbA1c, lipoprotein a ve idrar albümin kreatinin oranı için sağlıklı ve hastalık tanısı alan bireylerde farklı BV değerleri bulunduğuna bildirmişlerdir.

\section{Biyolojik varyasyon verileri üzerine mevcut veritabanları}

Biyolojik varyasyonun bileşenleri verilerinin her laboratuvarda üretilmesi gerekmemektedir, çünkü biyolojik varyasyon tahminleri tüm bireyler için sabit kabul edilmektedir. Analit aslında hastalığın etkisinde olsa bile, hastalık kronik ya da kararlı durumdaysa, CVI'nın sağlıklı kişilerle aynı büyüklükte olduğu varsayılmaktadır (1). Ancak homeostatik ayar noktalarında hastalık nedenli değişiklik olabilse de etrafındaki varyasyonlar değişmemektedir (1). Bu nedenle biyolojik varyasyon üzerine mevcut veritabanları tüm laboratuvarlarda kullanılabilir. İlk olarak John Ross, 1982'de kesinlik değerlendirmesi üzerine bir makale ile çalışmanın zaman aralığını, CVI ve CVG değerlerini 
bunlarla birlikte diğer indeksleri ve referansları listeleyen yayınlanmış verileri derlemiş, Callum Fraser ise 1988'de bu tip bir modeli izleyerek çalışmayı 1992'de güncellemiştir. Günümüze kadar çok sayıda analit için, biyolojik varyasyon hesaplamalarının yapıldığı çalışmaların olduğu bilinmektedir (15-17). Tüm mevcut biyolojik varyasyon hesaplamaları ilk olarak 1999 yılında Ricos ve arkadaşları tarafından derlenmiş ve bu konuyla ilgili her iki yılda bir güncellenen bir veritabanı oluşturulmuştur (17). Veri tabanının güncelleştirilmesi en son 2012 yılında yaklaşık 369 analit için yapılmıştır (http://www.westgard.com/biodatabase2012-update.htm) adresinde yer almaktadır (18). Ayrıca yine European Federation of Clinical Chemistry and Laboratory Medicine (EFLM) tarafından kurulan Biological Variation Working Group da yeni bir veritabanı oluşturmak için çalışmalar yürütmektedir

(https://www.eflm.eu/site/page/a/1148).

Bununla birlikte biyolojik varyasyonları henüz hesaplanmamış yüzlerce analit bulunmaktadır. İleride yapılacak olan çalışmalarda bu özel testlere odaklanmak gerekmektedir (18).

\section{Referans değişim değeri ve bireysellik indeksi}

Bir bireyin ardışık iki sonucu arasındaki değişikliğin klinik önemi değerlendirilirken analitik ve biyolojik varyasyon hesaplamaları dikkate alınır (preanalitik varyasyon ihmal edilebilir). Ardışık iki sonuç arasındaki değişikliğin klinik anlamlılığını nicelleştiren sayısal değer klasik olarak kritik fark veya RCV olarak bilinmekte (19) ve aşağıdaki formül ile hesaplanmaktadır:

$\mathrm{RCV}=\mathrm{k} \times \sqrt{ } 2 \sqrt{ }(\mathrm{CVA} 2+\mathrm{CVI} 2)$

Bu formülde k değeri \% 95 güven aralığı için 1,65 olarak belirlenmiştir. Yine CVA ve CVI sırasıyla analitik ve birey-içi varyasyon katsayısıdır (19). Bazı yazarlar bu formülün (karekök içindeki bölüm yerine $\mathrm{CV}(\mathrm{I}+\mathrm{A})$ da kullanmaktadır (20). Bu her iki formül ile elde edilen sonuçlar hemen hemen aynıdır. Laboratuvarların istenilen kalite değerlerine ulaşabilmesi için CVA $<<$ CVA olması gerektiğinden ve böylelikle esas olarak CVI'ya bağlı olduğundan, RCV değeri bütün laboratuvarlar için aynı kabul edilmektedir (17). Analitlerin çoğunluğunun yüksek bireyselliğinden dolayı (CVI < CVG) sağlık durumundaki değişiklikler için, RCV değerinin kullanılması popülasyona dayalı referans aralıkları kullanımından daha iyi bir yaklaşım olarak görünmektedir (15).

\section{Popülasyona dayalı referans değerlerin kullanı- labilirliğinin değerlendirilmesi}

Popülasyona dayalı referans değerler bireysellik indeksi (individuality index, II) ile adlandırılmakta olup CVI/CVG veya $(\mathrm{CVA}+\mathrm{CVI}) / \mathrm{CVG}$ oranı ile belirlenmektedir. Bu indeks 1'in altında olduğunda bir bireyin ardışık iki sonucu RCV' nin üzerinde fakat popülasyona dayalı referans aralıkların içinde yer alabilmektedir. Bireysellik indeksi 1 ' in üzerinde olan analitler için tek bir testin sonucunu, yalnızca popülasyona dayalı referans aralıkları ile karşılaştırmak yeterli olabilmektedir. $\mathrm{Bu}$ değerlendirme, bireysellik indeksinin 0,6 veya altında ve 1,4 veya üstünde olduğu durumlarda oldukça duyarlı görünmektedir (20).

\section{Sonuç}

Klinik olarak değerlendirilen hastalardan istenen ve yapılan analiz neticesinde mevcut durumda topluma dayalı referans aralıkları rehber alınarak düşük-normal-yüksek şeklinde değerlendirme yapılmakta ve gerekli durumlarda ileri araştırmalara yönlendirilmektedir. İleri araştırma gerekmeyen hastalarda ise mevcut sonuçlar göz önünde bulundurularak tedavi başlanmaktadır. Bireysellik İndeksleri ve Referans Değişim Değerlerinin belirlenmesi bir hastanın mevcut durumu hakkındaki değişiklikler konusunda klinisyeni daha doğru yönlendirmesine olanak sağlayacak belirteçler olup, topluma dayalı referans aralıklarının kullanılabilirliğinin, klinik olarak karar verme sürecine katkısını ve bir bireyden alınan ardışık numunelerin sonuçları arasındaki farkın önemini değerlendirmeye katkı sağlayacaktır. Bu uygulamalar yakın gelecekte rutin hizmet veren bütün laboratuvarlarda kullanılmaya başlanacak ve elde edilen laboratuvar sonuçlarının daha doğru yorumlanması ile ilgili faaliyetlerinin geliştirilmesine zemin oluşturacaktır.

Sonuç olarak mevcut derlemede bu ve buna benzer kullanım kolaylıklarının sağlanmasında yer almasından dolayı, biyolojik varyasyon, referans değişim değeri ve bireysellik indeksi hakkında bilgi sunduk.

\section{Çıkar çatışması /finansaldestek beyanı}

Bu yazıdaki hiçbir yazarın herhangi bir çıkar çatışması yoktur. Yazının herhangi bir finansal desteği yoktur.

\section{Kaynaklar}

1. Fraser CG. Biological variation: from principles to practice: Amer. Assoc. for Clinical Chemistry; 2001.

2. Peterson JC, Hill RH, Black RS, Winkelman J, Tholen D. Review of proficiency testing services for clinical laboratories in the United States-final report of a Technical Working Group. Division of Laboratory Systems, CDC, April. 2008.

3. Menditto A, Patriarca M, Magnusson B. Understanding the meaning of accuracy, trueness and precision. Accreditation and quality assurance. 2007; 12: 45-47.

4. Taga Y, Aslan D, Güner G, Kutay FZ. Tıbbi laboratuarlarda standardizasyon ve kalite yönetimi. Ankara, Türk Biyokimya Derneği Yayınları 2000; 106-23. 
5. Fraser CG. Inherent biological variation and reference values. Clinical Chemistry and Laboratory Medicine (CCLM) 2004; 42: 758-64.

6. Yılmaz FM, Kıral S. An underestimated preanalytical error source: Centrifuge temperature. Turkish Journal of Biochemistry 2013; 38.

7. Braga F, Panteghini M. Generation of data on within-subject biological variation in laboratory medicine: an update. Critical reviews in clinical laboratory sciences 2016; 53: 313-25.

8. Simundic A-M, Kackov S, Miler M, Fraser CG, Petersen PH. Terms and symbols used in studies on biological variation: the need for harmonization. Clinical chemistry 2015; 61: 438-39.

9. Ricos $C$, Jiménez $C V$, Hernández $A$, Simón $M$, Perich $C$, Alvarez $V$ et al. Biological variation in urine samples used for analyte measurements. Clinical chemistry 1994; 40: 472-77.

10. Fraser CG, Cummings ST, Wilkinson SP, Neville RG, Knox J, Ho $O$ et al. Biological variability of 26 clinical chemistry analytes in elderly people. Clinical chemistry. 1989; 35: 783-86.

11. Lacher D, Hughes J, Carroll MD. National health statistics reports. National Center for Health Statistic 2010; 21: 1999-2002.

12. Ricós $C$, Iglesias N, García-Lario J-V, Simón M, Cava F, Hernández $A$ et al. Within-subject biological variation in disease: collated data and clinical consequences. Annals of clinical biochemistry 2007; 44: 343-52.

13. Biosca C, Ricós C, Lauzurica R, Galimany R, Petersen PH. Reference change value concept combining two delta values to predict crises in renal posttransplantation. Clinical chemistry 2001; 47: 2146-48.
14. Sölétormos $G$, Semjonow $A$, Sibley $P E$, Lamerz R, Petersen $P H$, Albrecht $\mathrm{W}$ et al. Biological variation of total prostate-specific antigen: a survey of published estimates and consequences for clinical practice. Clinical Chemistry 2005; 51: 1342-51.

15. Fraser C. Biological variation in clinical chemistry. An update: collated data, 1988-1991. Archives of pathology \& laboratory medicine. 1992; 116: 916-23.

16. Sebastian-Gambaro MA, Liron-Hernandez FJ, Fuentes-Arderiu $X$. Intra-and inter-individual biological variability data bank. European journal of clinical chemistry and clinical biochemistry 1997; 35: 845-52.

17. Ricós C, Alvarez V, Cava F, Garcia-Lario J, Hernandez A, Jimenez $C$ et al. Current databases on biological variation: pros, cons and progress. Scandinavian journal of clinical and laboratory investigation. 1999; 59: 491-500.

18. Minchinela J, Ricós C, Perich C, Fernández-Calle P, Alvarez V, Domenech $\mathrm{M}$ et al. Biological variation database, and quality specifications for imprecision, bias and total error (desirable and minimum). The 2014 update. 2012.

19. Petersen PH, Rustad P. Prerequisites for establishing common reference intervals. Scandinavian journal of clinical and laboratory investigation 2004; 64: 285-92.

20. Ricos C, Cava F, García-Lario J, Hernandez A, Iglesias N, Jimenez $C$ et al. The reference change value: a proposal to interpret laboratory reports in serial testing based on biological variation. Scandinavian journal of clinical and laboratory investigation 2004; 64: 175-84. 